\title{
EMANCIPAÇÃO, ÉTICA E JUSTIÇA NA RELAÇÃO ENTRE ESPOSAS E MARIDOS DE PORTUGAL, BRASIL E CABO VERDE
}

\author{
Geruza Zelnys de Almeida (USP) \\ Kelly Cristina Marques (PUC/SP)
}

\begin{abstract}
RESUMO
O artigo analisa a tentativa de emancipação do Eu e a morte como resposta do/ao Outro na relação matrimonial, representada nos textos "Marido", da portuguesa Lídia Jorge; "A moça tecelâ", da brasileira Marina Colasanti e "Foram as dores que o mataram", da cabo-verdiana Dina Salustio. As representações da violência do homem/marido/opressor e da mulher/esposa/oprimida serão atravessadas pela proposta filosófico-ético-religiosa de Lévinas, que defende a sociabilidade com primazia no Outro como Rosto, no sentido de encontrar vestígios de motivação ética e de justiça nos fatos ficcionalizados.
\end{abstract}

PALAVRAS-CHAVE: emancipação, ética, justiça, alteridade.

\begin{abstract}
This article analyses the emancipation attempting of the self by having the death as an answer of/to the Other in the matrimonial relationship which is represented in the following shorts stories: "Marido" (Husband) from the Portuguese writer Lídia Jorge; "A moça tecelâ" (The weaver lady) from the Brazilian one Marina Colasanti and "Foram as dores que o mataram" (The pain killed him) from the Cape Verdean Dina Salustio. The violence representations of the man/husband/oppressor over the woman/wife/oppressed will be trespassed by the philosophical-ethical-religious Lévinas proposal, which defends the sociability to the Other as a Face primacy demand. In this way, it is a demand to find motivational traces of ethics and justice in the fictionalized facts (deaths).
\end{abstract}

KEYWORDS: emancipation, ethics, justice, alterity. 
A leitura que apresentamos é uma análise comparativa entre três contos de três diferentes autoras de língua portuguesa que se aproximam pela ficcionalização de temas relacionados ao universo feminino: a relação matrimonial e as formas de violência, física ou simbólica, praticadas pelos maridos contra suas esposas e, especialmente, a resposta elaborada por elas à situação violenta. ${ }^{1}$ Chamou nossa atenção, especialmente, a tentativa de emancipação, desde a relação matrimonial, do Eu, protagonista feminino oprimido, sobre o Outro, antagonista masculino opressor. Os textos escolhidos foram "Marido", da portuguesa Lídia Jorge; "A moça tecelã”, da brasileira Marina Colasanti e "Foram as dores que o mataram", da cabo-verdiana Dina Salustio. Apesar da distância geográfica, os três contos apresentam uma estrutura particularmente comum: o Outro (marido) é aquele que diante do $\mathrm{Eu}$ (esposa) - de quem parte a narração - não hesita em silenciar, escravizar e violentar. Perante essa situação, a mulher parece não ter outra saída, de modo que somente a morte, como resposta à violência física ou simbólica, é capaz de detê-lo.

À parte da abordagem feminista, procuramos atravessar essas representações com a proposta filosófico-ético-religiosa de Emmanuel Lévinas, filósofo lituano do século XX, que se ocupou em pensar as consequências de escolhas estéticas em relação à ética, tendo esta como instância primeira. Lévinas defende a sociabilidade com a primazia no Outro, no Rosto que surge em súplica e ordenação. Para ele, o primeiro mandamento seria: "não matarás", pois "eis-me aqui" como total vulnerabilidade. Isso porque a proposta do filósofo leva a uma reconsideração do mundo a partir da Ética, que desobriga da racionalidade ocidental e da ontologia porque a coloca antes de qualquer coisa, inclusive do pensamento. Essa posição, que alguns chamam antiintelectualista, apesar de fundar-se sobre conceitos como Rosto, Alteridade, Justiça, Responsabilidade, entre outros, busca liberar-se das certezas conceituais para ter seu fundamento na dor, ou seja, no sofrimento que antecede a razão e que não pode ser assimilado porque, como estrangeiro, vem de um lugar desconhecido.

Nesse sentido, a filosofia de Lévinas irmana-se à religião e passa a ter uma orientação litúrgica, pois o que realmente importa é o agir a serviço do Outro. A ordem não é dada por palavras, mas pela manifestação do Outro como alteridade absoluta que escapa à teoria, à tematização e à assimilação, uma vez que assimilar é trazer o Outro a si, destituindo-o de sua outridade.

Tal postura exige uma disposição radical para com o Outro, sem nada esperar a não ser a ingratidão, pois a perspectiva de igualdade eliminaria a essencial diferença entre eles, daí a necessidade de recusar qualquer recompensa ou ato semelhante que possam reconduzir o Outro ao Mesmo. A ideia é preservar a autonomia e a singularidade do Outro tanto no agir quanto no discurso, tanto na palavra quanto na arte. Esse importar-se transcendente requer, ainda, um responsabilizar-se integralmente por ele, assumindo, inclusive, toda a culpa por seu sofrimento, sem, contudo, es- 
perar uma economia de troca: somente o eu - com letra minúscula - carrega sob seus ombros o peso do Eu e do Outro. Trata-se, portanto, de uma relação assimétrica na qual é a demanda do Outro que reclama do Eu sua subjetividade e agir político no "exercício de um ofício não só totalmente gratuito, mas que requer, da parte de quem o exerce, uma oferta a fundo perdido" (LÉVINAS, 1993, p. 53).

No entanto, se o mandamento do Rosto é violado pelos maridos violentos (como será demonstrado no decorrer deste trabalho) o mesmo ocorre com as esposas que atentam contra a vida, pondo em risco a relação que, para o filósofo, seria a finalidade primeira do ser. O objetivo, portanto, é tentar entender como esses homicídios se relacionam com a motivação ética levinasiana, ou seja, como se dá a sujeição do Eu perante o Outro respeitando sua radical diferença e, assim, abrindo-se para um horizonte no qual brilharia a possibilidade de justiça.

É preciso lembrar que, de acordo com a assimetria da relação em Lévinas, é impossível haver justiça na paridade Eu-Outro. Somente a entrada do terceiro é capaz de diminuir suas arestas à medida que expande o Outro no Outro do Outro, despertando a consciência do Mesmo, fazendo com que clame pela relação justa: "O terceiro é o outro que o próximo, mas também um outro próximo, um próximo do outro e não somente seu semelhante..." (LÉVINAS, 1987, p. 232). Nesse sentido, nossa hipótese é de que haveria um movimento no discurso que vai da submissão à emancipação e que, desde esse novo lugar, o discurso emancipado assumiria a voz do terceiro, responsável pela Justiça. Porém, isso ocorre em alguns casos, já que, em outros, o que se tem é a impossibilidade ou somente a aparência de emancipação.

\section{DO OUTRO: UMA LEITURA DO MARIDO}

O conto "Marido", do livro Marido e outros contos (1997), de Lídia Jorge, apresenta a triste história de Lúcia, que vive uma rotina de espera pelo companheiro, que é mecânico e que não raro regressa de madrugada bêbado, marcado pela infidelidade e enlouquecido. Lúcia parece não se importar - ao contrário, quanto mais o marido a desmerece, mais ela se empenha em servi-lo arrastando os móveis para que não caia, cuidando para não irritá-lo e renovando seu prazer a cada retorno dele para casa:

Ela mesma estará junto da porta, e ele não precisará de chamar, porque a verá antes de qualquer outro objecto da casa. Ele há-de enxergá-la, mal entre [...] Sem arrastar nenhuns sapatos, sem espancar nenhum móvel. Vejam como ele vira, como o seu cabelo curto de homem lhe cai pela testa, como é bonito o lábio roxo do marido, sem som, só bafo. Ela até gosta do bafo a óleo e álcool. (JORGE, 1997, p. 21-22)

Esse ritual de submissão e abdicação é sacralizado à medida que o narrador envolve o discurso indireto livre com termos em latim e invo- 
cações que remetem à oração salve-rainha. Enquanto despreza a opinião dos moradores que a aconselham à separação, a esposa reflete sobre a vida conjugal e, especialmente, sobre sua dependência do marido como complemento indispensável para se sentir viva:

Era, e pôs-se a pensar sentada na cama, diante da vela por acender, que os habitantes daquele prédio de que era porteira lhe estendiam um tapete de negrume e solidão. Pensou como, para além do sacramento, seria triste a vida de porteira sem um marido que viesse da oficina-auto com o seu fato-macaco por tratar. Com quem ralharia, por quem iria ao talho, de quem falaria quando fosse às compras, para quem pediria protecção quando cantasse à janela por Salve Regina, a quem pertenceria quando os domingos viessem, e cada mulher saísse com seu homem, se ela nem mais teria o seu. A vida pareceu-lhe completamente absurda, como se todos se tivessem combinado para lhe arrancarem metade do corpo. Se, mal tinha deixado de ser criança, já procurava um homem, era porque de facto metade de si andava nesse homem desde sempre, por vontade de alguma coisa que o sacramento elevara mediante uma cerimônia. E agora, de repente, um conselho desses. Pensava a porteira, com a vela apagada, sentada na cama. Que ideia triste aquela de a assistente social dizer que uma mulher é um ser completo. (JORGE, 1997, p. 23)

Numa dessas noites, o marido a incendeia com a chama da vela das orações e, mesmo prestes a morrer, a mulher silencia aos outros e a si própria a culpa do marido, protegendo-o:

Afinal o que o marido queria não era incendiar-lhe o cabelo mas apenas acender a vela. Com os olhos abertos, sem ruído. Oh!, vela! Mater, vita, dulcedo, em silêncio como a noite quer, arde a vela. [...] Ele toma a vela, traz a vela do Rex e da Rainha até junto da porteira, puxa-lhe a roupa, aproxima a vela da camisa de nylon, com brilho e em silencio. Ateia. Ateou? Ateou a camisa? [...] Levem-na sem ruído, sem sirene, sem apito, sem camisa, sem cabelo, sem pele... (JORGE, 1997, p. 23-24)

Lúcia poderia ser o exemplo máximo da hospitalidade feminina que aparece nos estudos de Lévinas, seguido por Derrida. Sua motivação ética aparece no modo como toma para si a responsabilidade pelo Outro, carrega seu peso, suporta sua ingratidão e, a cada investida do marido contra si, sente que é convocada ao encontro.

Contudo, nota-se que a todo o momento Lúcia busca uma recompensa: ser notada pelo marido, ser alguém para ele assim como ele é tudo para ela. Mesmo quando parece rezar por ele, é para si que reza e pede porque somente pode ser com e através dele. Seu final trágico leva a crer 
que a primazia pelo Outro é apenas aparente, pelo menos nos moldes da filosofia levinasiana. Lúcia buscava no marido uma complementariedade, sentia-se em falta e almejava a totalidade. Por isso, a diferença fundamental na relação era assimilada por Lúcia, que a reduzia, em seu esforço de compreensão, alterando a alteridade do Outro a fim de torná-lo o Mesmo, ou seja, passível de ser identificado com um perfil de homem ao qual seu agir pudesse ser julgado "normal".

Esse encarceramento no em-si não permitiu espaço para a ação do Terceiro, cuja função é a de corrigir a assimetria do Rosto transfigurado na proximidade (LÉVINAS, 1987, p. 234). Só o Terceiro seria capaz aqui de desestabilizar a relação, provocando um exame de consciência: somos responsáveis pelo Outro e por todos os Outros, inclusive pelo Eu que é Outro de Outro. Lúcia não permitiu que ninguém interferisse na sua relação com o marido, negou a entrada do Terceiro, tomou para si a responsabilidade por sua morte, e talvez tenha cometido uma espécie de suicídio. Sua morte representa, portanto, o fracasso do encontro, da ética e da justiça.

\section{DO EU: UMA LEITURA DA MOÇA}

O conto "A moça tecelâ", do livro Doze reis e a moça no labirinto do vento (2001), de Marina Colasanti, relata por meio da atmosfera dos contos de fadas o cotidiano de uma jovem tecelã que podia tecer tudo, inclusive um marido de "chapéu emplumado, rosto barbado, corpo aprumado, sapato engraxado" (COLASANTI, 2003, p. 12) para fazer-lhe companhia. No entanto, assim que soube do poder mágico do tear, o homem passou a exigir que a esposa se isolasse e trabalhasse unicamente no sentido de satisfazer-lhe os desejos materiais:

E feliz foi, durante algum tempo. Mas se o homem tinha pensado em filhos, logo os esqueceu. Porque tinha descoberto o poder do tear, em nada mais pensou a não ser nas coisas todas que ele poderia lhe dar.

- Uma casa melhor é necessária - disse para a mulher. [...] Mas pronta a casa, já não lhe pareceu suficiente. - Para que ter casa, se podemos ter palácio? - perguntou. Sem querer resposta imediatamente ordenou que fosse de pedra com arremates em prata. (COLASANTI, 2003, p. 13)

A moça se submete por longo tempo à exploração e à violência simbólica até ser tomada pela tristeza e, posteriormente, se dar conta de que, assim como havia tecido, poderia destecer seu destino e tudo o que ele continha, inclusive o marido:

A noite acabava quando o marido estranhando a cama dura, acordou, e, espantado, olhou em volta. Não teve tempo de se levantar. Ela já desfazia o desenho escuro dos sapatos, e ele viu seus pés desaparecendo, sumin- 
do as pernas. Rápido, o nada subiu-lhe pelo corpo, tomou o peito aprumado, o emplumado chapéu. (COLASANTI, 2003, p. 14)

Uma noite, depois de destecer tudo o que havia tecido, entra no quarto do marido que, quando acorda, já é tarde demais, pois vê com assombro seu corpo sumir e a vida deixando-o. Depois disso, ela volta ao tear e, sozinha, começa a tecer uma nova manhã. Ou seja, ela desconstrói tudo que havia construído para si e começa uma nova vida do zero.

Embora o texto tenha um apelo feminista que poderia entender na atitude da moça sua emancipação, é fundamental apontar que isso se dá a partir da violação do mandamento máximo do Rosto: "não matarás". Afinal, por debaixo da atmosfera mágica, lê-se que a tecelã, no meio da noite e de surpresa, dá cabo da vida do marido e, a partir disso, devemos questionar se de fato podemos considerar essa uma postura emancipada.

A moça, sentindo-se sozinha e cansada da solidão do Mesmo, busca no Outro a diferença. No entanto, é marca dessa diferença perspectivas diferentes que culminam na violência praticada contra ela. Essa diferença radical entre eles - entre a visão de mundo do eu e do outro - é incompatível com a vida conjunta, mas não há enfrentamento nem tentativa de diálogo. Ao contrário disso, a postura de sujeição e submissão, que parece condizer com a primazia do Outro da proposta levinasiana, camufla a total falta de interação e o desprezo ao encontro, dada a forma como a tecelã evita o confronto, que seria natural na assimetria de uma relação na qual os seres não se perdem na fusão.

Sem tentar assimilar a diferença, o que poderia levá-la a transformá-lo no Mesmo, a moça o mantém Outro, porém impossível à relação idealizada como complementaridade. Diferente de Lúcia, a tecelã, frente ao impasse, dá cabo do Outro para manter-se a Mesma, reconhecível e segura, como o Eu do início, pronto a repetir a mesma postura futuramente: eliminar toda diferença sem abrir espaço para a entrada do Terceiro. Porque é preciso levar em conta que a tecelã não divide sua experiência com ninguém e, ao se decidir, simplesmente elimina o passado e começa algo do nada, sem deixar rastros do que foi.

Essa postura leva a crer que nada sobrou da experiência e que se trata de uma emancipação de fachada, mesmo porque não há espaço para a voz: não houve diálogo nenhum entre eles, o marido ordenava e ela obedecia. Em vista disso, pode-se deduzir que, uma vez que se relacione novamente com alguém, o risco de novamente ser subjugada é grande. Mais uma vez, vê-se fracassar a relação, a ética e a possibilidade de justiça.

\section{DO TERCEIRO: UMA LEITURA DAS DORES}

Ao contrário dos dois anteriores, o conto "Foram as dores que o mataram", do livro Mornas eram as noites (1999), de Dina Salustio, é o único em que a voz da esposa aparece para defesa de si contra a acusação de 
assassinato do marido. O leitor é colocado a par da violência praticada pelo marido, da esperança que ela nutria de que as coisas mudariam e de como, apesar de tudo, o amava:

Não matei o meu marido.

Eu amava-o. Por quê matá-lo?

Foram as dores do meu corpo que o condenaram. Foram o sangue pisado, o ventre moído, as feridas em pus.

Foram as pancadas de ontem, as de hoje e, sobretudo, as pancadas de amanhã que o mataram.

Eu amava-o. Por quê matá-lo?

Foi o meu corpo recusado e dolorido após o uso e os abusos. Foram a tristeza, o desespero e a dor o amor que não tinha troco.

Eu amava-o. Por quê matá-lo? (SALUSTIO, 1999, p. 17)

A autodefesa aos poucos adquire a forma de uma acusação: "Ele matou-se. Criou um espaço onde coabitavam a violência, a destruição, a miséria, o animalesco. E nós. Deu-me as armas e fez-me assassina." (SALUSTIO, 1999, p. 18).

Nota-se, aqui, uma situação radicalmente nova em relação às duas anteriores. A personagem cabo-verdiana, em oposição à Lúcia, não assimila a diferença e, em oposição à tecelã, não a apaga magicamente. Sua relação com o Outro, que se tornou dramática por conta da violência e do abandono, é marcada pela assimetria de um amor não totalizante feita dos momentos que se amaram. Não há expectativa de completude e mesmo sua espera não se inscreve numa economia de troca: trata-se de uma espera que é desejo e não necessidade:

Às vezes ficava à janela, meio escondida, vendo-o partir para o trabalho com a roupa que eu lavara e engomara. Gostava do seu modo de andar, do jeito como inclinava a cabeça. Via-o partir e ali ficava horas e dias à espera que voltasse e me trouxesse um riso e a esperança de que as coisas iriam mudar. Nesse dia não lembraria mais os tempos duros, os paus de pedra que me roíam e me desgastavam as entranhas. Mas para mim, não voltava nunca. Apenas para pedaços do meu corpo que esquecia logo. (SALUSTIO, 1999, p. 17)

A necessidade "é o próprio retorno, a ansiedade do eu por si, egoísmo, forma original de identificação, assimilação do mundo, em vista da coincidência consigo, em vista da felicidade" (LÉVINAS, 1993, p. 55). A necessidade satisfeita se fecha na totalidade. O desejo, ao contrário, é abertura, não pode ser satisfeito: é desejo pelo desejo, ou ainda, espera pela esperança: "ali ficava horas e dias à espera que voltasse e me trouxesse um riso e a esperança de que as coisas iriam mudar" (grifos nossos). A esse 
desejo desinteressado, Lévinas associa a bondade: "Não como um Desejo que a posse do Desejável apazigua, mas como o Desejo do Infinito que o Desejável suscita, em vez de satisfazer. Desejo perfeitamente desinteressado - bondade" (LÉVINAS, 2000, p. 37).

A partir disso, questionamos: como essa personagem, cuja bondade a torna tão próxima da ética reivindicada pelo filósofo, atenta contra o mandamento primeiro do Rosto, matando seu companheiro?

Supomos, graças à construção narrativa que se faz em dois pontos de vista - ora em terceira, ora em primeira pessoa sem marcas que indiquem essa mudança das vozes - que a relação Eu-Outro é atravessada pelo surgimento do Terceiro, como autoconsciência do Eu frente à violência exercida pelo Outro, provocando a exteriorização da relação para a dimensão social:

Na relação com o outro sempre estou em relação com o terceiro. Mas ele é também meu próximo. A partir deste momento, a proximidade torna-se problemática: é preciso comparar, pesar, pensar, é preciso fazer justiça, fonte da teoria. Toda a recuperação das instituições [...] se faz, a meu ver, a partir do terceiro. [...] $\mathrm{O}$ termo justiça aplica-se muito mais à relação com o terceiro do que à relação com o outro. [...]

Se só houvesse o outro diante de mim, diria até o fim: devo-lhe tudo. Sou para ele. E isto vale inclusive para o mal que me faz: não sou seu semelhante, estou para sempre sujeito a ele. Minha resistência começa quando o mal que me faz é feito contra um terceiro que é também meu próximo. É o terceiro que é a fonte da justiça e, por aí, da repressão justificada; é a violência sofrida pelo terceiro que justifica que se pare com violência a violência do outro. (LÉVINAS, 2002, p. 119-121)

Se entendemos a proposta levinasiana, no processo de emancipação que é a tomada de consciência de si, a personagem abriria espaço para um Terceiro virtualizado que observa a relação e a vê como Outro do Outro e, desde aí, não permite mais que a violência seja praticada. Por isso, a personagem não muda sua posição de responsabilidade frente ao Outro, da proposta de Lévinas: ela sente que ele matou-se a si pelas mãos dela. Ele tornou-a assassina, mas não foi ela quem o matou: foram as dores.

Diferente de Lúcia, a personagem portuguesa que inspira pena, e a tecelã brasileira, que inspira admiração, a personagem sem nome cabo-verdiana inspira compaixão ao mostrar sua total fragilidade e vulnerabilidade, lançando-se ao infinito e imprevisível de uma relação com o Outro para sempre desconhecido e inassimilável. 
Evidentemente, não estamos absolvendo a personagem ou dizendo que agiu corretamente, muito menos homenageando essa forma de emancipação (se é que é uma emancipação). O que tentamos é olhar para a cena que se constrói e tentar compreender a agência desses atores: marido, esposa e sua duplicação no Terceiro que comete o ato homicida em legítima defesa. É interessante atentar para o que ela diz em seu depoimento "Deu-me as armas e fez-me assassina. ... depois ficou tudo escuro" (SALUSTIO, 1999, p. 18). A escuridão sugere a entrada do Terceiro que, para Lévinas, é a transcendência por excelência, ou, em última instância, Deus.

Se "não existe bondade, mas ela acontece" (HADDOCK-LOBO, 2012, p. 115) na relação ética com o Rosto, nesse conto de Dina Salustio, vemos também o acontecimento da justiça nascendo da relação política ordenada pelo surgimento do Terceiro, ou ainda, do ser em sociedade.

\section{SUBMISSÃO E LIBERTAÇÃO NA FORMA LITERÁRIA}

A partir dessas considerações, algumas questões se colocam sobre a forma literária, afinal estamos pensando essas questões através de um gênero que está preso a uma forma específica e ela também precisa ser lida. Ainda mais porque se trata de um gênero híbrido que se mescla a outros que também falam com e por meio dele.

Lévinas tem um pensamento sobre a linguagem que a divide entre o Dito e o Dizer, no qual o primeiro aproxima-se da designação ou nominação e dá acabamento às coisas; e o segundo, ligado à modalidade verbal, que antecede o Dito viciado e aproxima-se mais da intuição e do sensível do que da consciência interessada. ${ }^{2}$ O Dizer, então, é posto em paralelo ao aparecimento do rosto que não se pode apreender porque não visa convencer ou transmitir conteúdos/verdades, mas apenas expressar-se. Já no Dito estaria toda a herança do ser, inclusive aquilo que possibilita sua repetição e continuidade.

Isso posto, caberia perguntar até que ponto o Dizer enrosca-se no Dito, que pode estar associado nesse caso à forma fixada pelo gênero, trabalhando pela manutenção de certas "verdades" comportamentais ou discursivas. Nesse sentido, talvez o conto de Lídia Jorge, caminhando junto ao gênero prece/oração, já traria no bojo da forma as marcas da submissão, pois, em última instância, se apresenta ao leitor como um pedido, seja de proteção, benção ou mesmo perdão diante do que se diz, potencializando, assim, sua carga imagética. $\mathrm{O}$ que nos preocupa e estimula à reflexão são as implicações dessa forma no discurso e no agir da personagem, ou seja, em que medida esse dizer está tão imbricado no dito da forma que dele não consegue se desvencilhar? Em que medida essa mulher não pode emancipar-se porque está presa a uma estrutura que só através da morte é capaz de se libertar? 
Já o conto de Marina Colasanti, que se mistura ao mito e/ou ao conto-de-fadas, traria na sua forma as marcas de uma narrativa para ser repetida sem ser questionada. Assim, apesar de explicitamente propor uma subversão, como comumente ocorre nas releituras dessa modalidade textual, a voz que fala no conto também está sujeita à eterna repetição de discursos e comportamentos cristalizados. Disfarçado de outro, seu dizer, a cada tentativa de desdizer o dito, o traz consigo revivificando-o eternamente.

Assim, quando Dina Salustio mescla seu conto ao depoimento, acaba construindo também um espaço propício à intimidade, porém marcado pela vulnerabilidade inscrita no juramento de verdade. De certa maneira, essa fragilidade, resultado da total exposição do ser ao Outro que o julga, transforma-se em força e potência obrigando a um novo olhar para esse discurso e, talvez até, sua pronta absolvição. Conta o popular, "quem diz a verdade não merece castigo": a imagem de verdade, inscrita no hibridismo dos gêneros, humaniza o julgamento da personagem.

Em vista disso, pensamos que é tarefa da crítica propiciar o movimento contínuo do Dizer no Dito e fazer reverberar o Dizer do Dito, buscando desnudar as estruturas responsáveis pelo processo de submissão e emancipação daquele que diz. Talvez assim a crítica literária possa, eticamente, colaborar na promoção de um espaço de (des)construção de forças e ideologias que, da ficção, se exteriorize para o real.

\section{REFERÊNCIAS BIBLIOGRÁFICAS}

COLASANTI, Marina. Doze reis e a moça no labirinto do vento. São Paulo: Global Editora, 2003.

FARIAS, André Brayner de. O infinito pode ser estético? Entre o silêncio e o dizer - itinerários da arte em Lévinas. In: Veritas, Porto Alegre, v. 52, n. 2, Jun 2007, p. 5-21. Disponível em:

http://revistaseletronicas.pucrs.br/ojs/index.php/veritas/article/ view/2072/1566 Acesso em 10/11/2012.

HADDOCK-LOBO, Rafael. A Herança da Ética de Emmanuel Lévinas por detrás da Desconstrução do Direito de Jacques Derrida. In: Cadernos da EMARF, Fenomenologia e Direito, Rio de Janeiro, v.4, n.2, p.1-152, out.2011/mar.2012, p. 103-115. Disponível: http://www.ifcs.ufrj.br/ sfjp/ revista/downloads/a_heranca_da_etica_de_emmanuel_levinas.pdf Acesso em 13/07/2012.

JORGE, Lídia. Marido e outros contos. Publicações D. Quixote - Leya, 1997.

LÉVINAS, Emmanuel. De Otro Modo Que Ser, O Más Allá de la Esencia. Salamanca: Ediciones Sígueme, 1987.

. Humanismo do outro homem. Lisboa: Edições 70, 1993. 
. De Deus que vem à Ideia. Petrópolis: Vozes, 2002.

SALUSTIO, Dina. Mornas eram as noites. Cabo Verde: Instituto Caboverdiano do Livro e do Disco, 1994.

Recebido para publicação em 14/10/2012

Aprovado em 20/01/2013

\section{NOTAS}

1 Uma versão reduzida desse artigo foi apresentada como comunicação no I Congresso Internacional Portugal-Brasil-África, realizado na Universidade da Beira Interior (Covilhã, Portugal, 2012).

2 Evidentemente, trata-se de uma questão muito mais complexa que defende a superioridade do verbo sobre os substantivo. Isso está bem colocado no artigo de André Brayner de Farias, quando o autor diz: "É a verbalidade do verbo que ressoa na proposição predicativa e é, secundariamente, em razão de sua ostentação privilegiada no tempo, que o dinamismo dos entes se designa e se exprime pelos verbos. O esforço em vista de levar os verbos a exercer a função de signos supõe, ingenuamente, como original a divisão dos entes em substância, de uma parte, e em acontecimentos de outra, em estático e em dinâmico. Ou a ligação entre o Dito e o ser não se conduz sem resíduo à designação" (LÉVINAS apud FARIAS, 2002, p. 12). 